\title{
VARIAÇÃO E DIVERSIDADE LINGUÍSTICA NO ENSINO-APRENDIZAGEM DE LÍNGUA INGLESA NA GRADUAÇÃO EM LETRAS
}

\author{
Ubiratã Kickhöfel Alves \\ Elisa Battisti
}

\begin{abstract}
RESUMO
$\mathrm{O}$ artigo trata de um projeto de ensino voltado à variação e diversidade linguística na formação de profissionais de língua inglesa na graduação em Letras. Caracteriza-se o processo de variaçáo linguística nas línguas naturais, abordam-se fatos variáveis da língua inglesa e apresentam-se a fundamentação, o desenvolvimento e os resultados do projeto de ensino.
\end{abstract}

PALAVRAS-CHAVE: variação linguística; língua inglesa; graduação em Letras.

\section{Introdução}

adequada formação, na graduação em Letras, do profissional de língua
inglesa, tanto na Licenciatura quanto no Bacharelado, implica abordar
um aspecto inerente a todas as línguas naturais, principalmente em sua
modalidade falada: a variaçáo e diversidade linguística. Elas abrangem o pro-
cesso de alternância entre formas equivalentes de dizer a mesma coisa (you -ya
'você', want to - wanna 'querer', car - ca: 'carro', entre muitas outras realizaçôes
alternantes possíveis) e o produto desse processo, as variedades de inglês faladas
no mundo em diferentes países/regióes (inglês australiano e inglês americano,
inglês texano e inglês do leste dos EUA, por exemplo), diferentes estratos so-
ciais (como o inglês negro americano, o inglês dos jovens), diferentes níveis de
linguagem ou registro (inglês coloquial ou vernacular, inglês formal), como se 
evidencia em programas de rádio e TV, canções, filmes e livros. Essa formação capacita o profissional de língua inglesa - professores, tradutores, especialistas no idioma - a reconhecer e lidar com as variedades faladas ao redor do globo, concebendo a língua como um organismo dinâmico que varia e muda ao longo do tempo por força do uso e em decorrência de pressóes tanto sociais - classe, gênero, idade, localização geográfica dos falantes - quanto linguísticas - tais quais a posição da forma nos sintagmas, o tipo de base a que se anexam os morfemas, as características fonéticas dos sons vizinhos.

O ensino tradicional de língua inglesa, em cursos livres e nos próprios ambientes universitários, tende, entretanto, a priorizar apenas uma variedade da língua. Dependendo do material didático utilizado, essa variedade é a britânica ou a americana, em seu registro formal e conforme um padrão, isto é, sem características linguísticas que identificariam o usuário como originário desta ou daquela regiáo, pertencente a uma dada classe social, com uma certa idade e gênero. É esse padrão o que as regras da gramática (normativa) expressam. Tal fato, de certo modo, justifica-se porque é a partir do domínio da variedade padrão que o aprendiz da língua poderá ascender socialmente, pela aprovação em exames internacionais e em seleçóes de emprego. Nesse sentido, exige-se do profissional de língua inglesa um conhecimento detalhado acerca de tal variedade.

No entanto, a visão monolítica que assim se desenvolve pode levar tanto o professor quanto seus alunos a adquirirem uma versão artificial da língua, distante daquelas efetivamente usadas nas situaçôes sociais cotidianas. Pior do que isso, pode levá-los a considerarem o que se desvia do previsto pelas regras da gramática padrão como algo feio, errado, ruim. É preciso que o profissional de língua inglesa reconheça outras variedades da língua além daquela constante nos manuais e desenvolva capacidades para operar com elas, o que, por seu turno, pode contribuir para que as tradicionais noçóes de "certo" e "errado", típicas das salas de aula de língua, sejam substituídas por "mais ou menos adequadas" em relação aos usuários e a condiçóes de uso específicas.

A teoria sociolinguística em suas diferentes versóes (LABOV 1972, 1994, 2001; BLOM e GUMPERZ 2002[1972]; ECKERT 2000), abordada em programas de diferentes disciplinas da graduação em Letras, fornece o embasamento conceitual necessário ao profissional em formação para que ele possa refletir sobre o papel das variedades da língua inglesa nos usos da língua 
por falantes nativos. Entretanto, nossa experiência como professores de inglês mostra que, muitas vezes, os graduandos não se mostram capazes de relacionar os conteúdos de sociolinguística aos conhecimentos linguísticos das aulas de língua inglesa. De fato, ainda que ambas as áreas estejam estreitamente relacionadas, a impressão que temos, ao trabalhar com aprendizes de inglês, é que tais alunos tendem a segmentar as áreas de conhecimento com que têm contato ao longo do curso de graduaçáo. Acreditamos que tal dificuldade seja, em parte, deficiência dos programas das disciplinas por eles cursadas, uma vez que as áreas de conhecimento tendem a ser apresentadas separadamente, havendo poucas oportunidades de discussão interdisciplinar.

Diante da problemática acima exposta, elaborou-se um projeto de ensino cuja fundamentação, desenvolvimento e resultados são o tema deste artigo. O projeto foi desenvolvido na Universidade Federal do Rio Grande do Sul (UFRGS) no primeiro semestre de 2012, com o propósito maior de estreitar os laços entre o conhecimento teórico sociolinguístico e o conhecimento de língua inglesa presentes na formação do profissional ao longo do curso de graduação em Letras. $\mathrm{O}$ projeto propõe uma inovação na cadeira de Língua Inglesa V, disciplina que, nos currículos de Letras-Inglês/Bacharelado ou Licenciatura da UFRGS, passa a ter, como um de seus conteúdos programáticos, uma introdução à noção de variação linguística na língua inglesa. Trata-se de um módulo pedagógico em que os graduandos discutem conceitos da teoria sociolinguística aplicados a fatos variáveis da língua em questão.

O artigo estrutura-se da seguinte forma: a próxima seção traz fatos de variação e diversidade linguística que ilustram a base conceitual e dão consistência à ideia, aqui defendida, de que variação sociolinguística e seus resultados devam fazer parte da formação do profissional de modo mais efetivo. Essa seção sustenta-se em diferentes fontes ${ }^{1}$ de teoria e análise sociolinguística, muitas das quais não referidas explicitamente no texto para lhe conferir fluidez. As seçóes seguintes apresentam o projeto de ensino em suas diferentes fases de execução e os resultados alcançados. Na última seção, são apresentadas nossas conclusões.

1 Ver a seção Referências, ao final do artigo. 


\section{Variação e diversidade linguística}

Qualquer língua natural apresenta instabilidade na estabilidade: ao lado de um corpo maior de constituintes cuja realização é categórica ou invariável, há algumas formas linguísticas em alternância. Por exemplo, na língua inglesa, a realização de $[\mathrm{r}]$ em final de sílaba alterna com sua não realização: $c a r-c a$ : 'carro', market-ma:ket 'mercado', door-doo: 'porta', comfortable-comfo:table 'confortável'. Não se trata de variação eventual, restrita a alguns vocábulos. É um processo que pode afetar todos os vocábulos em que esse segmento em específico, /r/, ocupe uma dada posição silábica - final de sílaba, tecnicamente denominado coda. Outras consoantes em coda náo apresentam realizaçáo alternante em língua inglesa.

Esse caráter sistemático ou não fortuito da variação linguística motivou o sociolinguista americano William Labov, desde seus primeiros trabalhos sobre variação linguística, especialmente em seu livro Padrôes Sociolinguisticos, de 1972, a entendê-la como resultado da aplicação de regras variáveis que afetariam classes inteiras de segmentos ou constituintes em dados ambientes. Foi também essa sistematicidade que lhe permitiu tomar a variação como etapa da trajetória de mudança de uma língua: se, após geraçóes, uma das formas em alternância seguir sendo usada e a outra, não, ocorrerá a mudança linguística.

As regras variáveis são normas de uso, compartilhadas pelos membros de comunidades de fala. Não são necessariamente ensinadas na escola, mas adquiridas ao nos comunicarmos, ao ouvirmos falar, ao falarmos. O emprego preponderante de uma ou outra das formas alternantes numa comunidade de fala pode diferenciar seu falar do de outra comunidade, contribuindo para que se desenhem os contornos de um dialeto ou variedade da língua, assim resultando na diversidade linguística referida no presente trabalho. Por exemplo, a não realização preponderante de /r/ em coda silábica é um dos traços de variedades do inglês britânico, a realização preponderante de /r/ é um dos traços de variedades do inglês americano. Como veremos adiante (seçáo 3.1), no inglês americano, $\mathrm{o} / \mathrm{r} /$ tende a ser realizado em comunidades de fala cujos membros pertencem a estratos socioeconômicos mais altos, e a náo ser realizado na fala de grupos pertencentes a classes sociais mais baixas. No primeiro caso, a variação na realizaçáo do /r/ é um dos traços que distinguem variedades 
geográficas ou regionais. No segundo caso, o processo distingue variedades ou dialetos sociais.

As línguas do mundo são, então, conjuntos de falares, de variedades geográficas ou sociais. Apesar de aparentemente assumirem traços individuais, as variedades se conformam a padróes de uso dos grupos sociais que os falantes integram, como resultado do compartilhamento tácito de normas linguísticas nessas comunidades de fala. É o que o tratamento estatístico de grandes quantidades de dados de fala feito pelos sociolinguistas tem mostrado. Há correlaçáo, estatisticamente comprovada, das tendências de uso das formas em variação com características sociais dos usuários da língua (idade, gênero, grau de escolaridade dos falantes, por exemplo) e com aspectos da própria língua (sonoros, vocabulares, oracionais).

Se assim é, não se pode dizer que as variantes tenham, elas mesmas, um valor. Elas adquirem valor social pela associação que se faz entre elas e seus usuários, entre elas e as situaçóes sociais em que são empregadas, sobre as quais há um conjunto de expectativas. Bonito ou feio, superficial, sofisticado, elegante, descolado, rústico, caipira, jovem, velho, entre muitos outros, são adjetivos que empregamos para qualificar as variantes, os falantes e a situação em que foram usadas, de acordo com nossa própria percepçáo.

Já certo e errado são noçóes derivadas das práticas escolares, do contato com a variedade padrão da língua e com as regras da gramática normativa. Dependem, portanto, do conhecimento das orientaçóes de uso constantes nessas liçóes. Muitos falantes empregam formas alternantes incorretas para a gramática, mas esperadas em seu grupo. Vem daí que prestígio - ou valor social positivo atribuído tanto a variantes quanto a seus usuários - é um conceito relativo aos sujeitos falantes, a seus grupos, à adequação do emprego das formas em diferentes situaçóes sociais, não necessariamente relacionado à correção gramatical.

As liçóes escolares sobre regras gramaticais podem refrear processos de variação e mudança linguística. No entanto, boa parte das alternâncias, principalmente as fonético-fonológicas, passa despercebida dos próprios falantes e escapa das sançôes gramaticais. Outras formas alternantes, inicialmente não previstas pelas regras normativas e por elas condenadas, adquirem prestígio social e passam a ser amplamente usadas. É o que lhes confere potencial para, no decorrer de geraçóes, resultar em mudança linguística, sobre o que a língua inglesa nos fornece bons exemplos. 


\section{Alguns fatos de variação, mudança linguística e diversidade na língua inglesa}

A língua inglesa tal qual hoje a conhecemos tem pelo menos quinze séculos de existência, ao longo dos quais passou por processos de variação e mudança linguística. Foi introduzida na Bretanha há aproximadamente 1500 anos por invasores do Mar do Norte. Inicialmente analfabetos, esses invasores adquiriram a escrita em alguns séculos, com o que começaram a escrever crônicas históricas, textos religiosos, registros administrativos, textos literários. Reconhecendo-se pelo menos quatro grandes períodos evolutivos - Old English (Inglês Antigo), Middle English (Inglês [do final] da Idade Média), Early Modern English (Inglês Moderno Inicial), e Modern English (Inglês Moderno) - e comparando registros escritos disponíveis, pôde-se constatar que a língua inglesa sofreu transformaçóes substanciais de natureza fonético-fonológica (em sua sonoridade), morfológica (no formato das palavras) e sintática (na ordem dos elementos nas oraçôes).

A trajetória da realização do $/ \mathrm{r} / \mathrm{em}$ coda na história da língua inglesa, por exemplo, auxilia a compreender o padrão de variação hoje verificado em seus diferentes falares. A partir de dados de registros escritos, pode-se afirmar, resumidamente, que, de 1300 a 1715, a náo realização de /r/ era variável e esporádica. Em geral, ocorria em sílaba tônica, posição pré-consonantal, sem que a vogal-núcleo da sílaba alongasse (arse $>$ ass, 'nádegas e ânus'). De $1640 \mathrm{em}$ diante, há registro de que o $/ \mathrm{r} / \mathrm{em}$ coda tenha se enfraquecido, e depois (1680) iniciou-se o alongamento vocálico compensatório, mas não em posição final (em barge 'barcaça', mas não em bar, 'barra', 'bar'). De 1740 a 1790, houve a perda esporádica de /r/, com alongamento estável da vogal. Após 1790, com o alongamento vocálico já estabilizado, a não realização de /r/ generalizou-se, sendo ele só eventualmente realizado. Ou seja, ainda existia variação entre realização e não realização de /r/ em coda no final do século XVIII, mas com o predomínio da forma sem a realização do $/ \mathrm{r} /$.

Como a expansão da nação inglesa para outros territórios se deu ao longo das etapas de variaçáo e mudança do $/ \mathrm{r} /$, os falares de língua inglesa levados para o Oriente, para a Austrália, África e América eram levemente distintos em relação a esse processo variável. Nas novas terras, seguiram seus próprios rumos evolutivos, por força de condiçóes sociais e linguísticas específicas. 
Hoje, pode-se dizer que todos os dialetos da língua inglesa têm um fonema $/ \mathrm{r} /$, que neles não se distribui igualmente. Nos dialetos ou variedades róticas, $\mathrm{o}$ $/ \mathrm{r} /$ realiza-se em todas as posiçóes, no início e no final de sílaba (red 'vermelho', very 'muito', part 'parte', far 'longe'). Nas variedades não-róticas, o / $\mathrm{r} /$ realiza-se só no início da sílaba (em red, very, mas não em part, far).

Assim, Escócia, Irlanda, sudoeste da Inglaterra, uma porção de Lancashire do Oeste, a maior parte dos Estados Unidos e o Canadá são róticos. O restante da Inglaterra, partes da costa leste dos Estados Unidos e costa do Golfo, África do Sul, Austrália e Nova Zelândia são não róticos. Essa distribuição mostra o papel da realizaçáo variável do /r/ em coda na constituição de variedades geográficas de língua inglesa. Já a análise do processo em um falar contemporâneo de língua inglesa revela seu papel na constituição de variedades sociais desta língua.

Em Nova Iorque, Estados Unidos, nos anos 1960, William Labov realiza uma pesquisa pioneira sobre o uso da língua em seu contexto social natural, sem observação explícita. O objeto de sua análise é a realizaçâo do /r/ em coda. $\mathrm{O}$ pesquisador partiu da observação preliminar de que a variação na realização do /r/ em coda era, à época, um diferenciador social em todos os níveis de fala. A realização do /r/ era um novo padrão de prestígio que vinha se impondo no inglês falado em Nova Iorque.

Labov e sua equipe coletaram dados em três lojas de departamento, frequentadas por clientela de diferente status social: Sak's (status superior), Macy's (status médio), S.Klein (status inferior). O entrevistador fazia-se passar por um comprador perdido na loja, buscando localizar produtos num andar específico. Perguntava aos vendedores onde encontrá-los, e a resposta era fourth floor (quarto andar), ambas as palavras com $/ \mathrm{r} / \mathrm{em}$ coda, posição medial e final. Como os pesquisadores simulavam não ter ouvido direito, os empregados forneciam uma primeira resposta (dado de fala natural, espontânea), depois, repetiam-na, com um pouco mais de ênfase (dado de fala enfática). Os resultados da pesquisa mostraram que $62 \%$ dos empregados da Saks, $51 \%$ da Macy's e $21 \%$ da S.Klein realizaram $/ \mathrm{r} / \mathrm{em}$ coda em pelo menos uma das duas palavras da resposta. No estilo enfático, o /r/ é mais frequente na fala de todos os empregados, principalmente se são da Macy's e da S.Klein. O /r/ deixa de ser mais frequentemente realizado na fala dos mais idosos e de ocupação de menor status (repositores) nas lojas. 
A conclusão de Labov e sua equipe sobre a realização variável de /r/ em coda no inglês de Nova Iorque foi a de que ela é estratificada: tende a aumentar à medida que se eleva o status da loja, o que mostra que a realização de /r/ em coda tem prestígio nessa comunidade de fala. O prestígio e a expansão dessa realização são inovaçóes da fala local, evidenciadas pelo fato de os empregados mais jovens e de cargos mais altos nas lojas serem os maiores usuários da alternante.

A caracterização da variação linguística empreendida nesta seção, bem como a abordagem de alguns fatos da história e evolução da língua inglesa, tiveram o propósito de mostrar que o processo (variação) e seus resultados (a diversidade de variedades da língua) são algo esperado e natural nas línguas do mundo, não podendo ser negligenciados no ensino-aprendizagem de língua inglesa e na formação do profissional da área. Em termos de conteúdo, os tópicos que acabamos de abordar foram tratados na execução do projeto de ensino, descrito na próxima seção. A diferença está nos exemplos explorados, que não foram apenas de natureza fonético-fonológica (como a realização do /r/ em coda), como se fez aqui para otimizar as informaçôes fornecidas, mas que envolveram, também, os de natureza morfológica e sintática. Passemos, então, a tratar do projeto de ensino.

\section{O projeto de ensino}

O projeto de ensino teve o objetivo não somente de prover insumos teóricos a respeito dos conceitos de variação e diversidade linguística, mas também de envolver os alunos em atividades práticas, com trabalhos elaborados por eles, a partir dos quais pudessem operar com dados linguísticos referentes aos conceitos recebidos.

O projeto foi desenvolvido no primeiro semestre de 2012, junto a uma turma da disciplina de Língua Inglesa $\mathrm{V}$ do curso de graduação em Letras ( $\mathrm{Li}$ cenciatura e Bacharelado) da UFRGS. A classe tinha como docente responsável um dos autores deste artigo. Sendo a turma de quinto semestre, esperava-se dos discentes um nível pré-avançado de proficiência em inglês. Os aprendizes em questão já haviam cursado disciplinas da área de Linguística, em que se abordaram noções de variação linguística. Apesar disso, os aprendizes nunca haviam estudado sistematicamente fatos variáveis da Língua Inglesa. 
A turma era constituída por 20 alunos. Todos participaram do projeto em sua etapa de intervenção pedagógica, que transcorreu durante os encontros da disciplina. Todos foram, também, convidados a preencher os questionários de sondagem e avaliação do curso (a serem explicitados nas próximas seçôes), mas apenas 12 participaram assiduamente dessas etapas do projeto. Neste trabalho, serão consideradas, por essa razão, as respostas fornecidas por esses 12 aprendizes.

O projeto pode ser sistematizado em três etapas: (a) pré-inicial, em que, por meio de um questionário de sondagem, puderam ser verificadas as necessidades e os interesses dos aprendizes participantes em relação à sociolinguística, variação e diversidade linguística; (b) execução pedagógica do projeto, caracterizada pela discussão dos conceitos de sociolinguística aplicados à língua inglesa e pelo desenvolvimento, pelos alunos, de atividades com dados variáveis do inglês; (c) avaliação do projeto, realizada através de questionários distribuídos aos alunos ao término das atividades.

$\mathrm{Na}$ etapa pré-inicial do projeto de ensino, os aprendizes foram convidados a responder a um questionário de sondagem em que poderiam expressar suas concepçôes prévias sobre variação e diversidade linguística. Com ele, objetivávamos verificar se os alunos tinham claras as diferenças, bem como os pontos de convergência, entre essas noçóes.

As respostas permitiram-nos levantar aspectos-chave para a própria execuçáo do projeto de ensino. Verificamos, sobretudo, que, apesar de os aprendizes afirmarem já terem tido algum contato com "variaçăo linguística" e "diversidade linguística", apresentaram alguma dificuldade para caracterizar e exemplificar ambos os termos, que acabavam sendo confundidos. Na verdade, mais da metade dos aprendizes admitiram que conheciam o termo "diversidade linguística" parcialmente. Verificamos que, na maioria dos casos, "diversidade linguística" era tida como "diferentes meios de comunicação", "diversas formas de uma língua", "muitas maneiras de falar/escrever".

Verificamos, também, que, embora já tivesse ocorrido um primeiro contato com o conceito de diversidade linguística, os alunos ainda não haviam tido a oportunidade de refletir sobre ele na aula de língua estrangeira.

$\mathrm{Na}$ segunda etapa, foram discutidos com os alunos conceitos de Sociolinguística com base em processos variáveis da língua inglesa, de natureza morfossintática e fonológica, os mesmos abordados na segunda seção do 
presente artigo. Em seguida, solicitou-se que os alunos desenvolvessem um projeto sobre as variedades de língua inglesa nas artes - em grupos, deveriam buscar trechos de canções e de filmes que representassem uma variedade de língua inglesa. Finalmente, ao término do semestre, promoveu-se uma reflexão a respeito das variedades do inglês.

Após a execução do projeto pedagógico, ao final do semestre letivo, solicitamos que os alunos preenchessem outro questionário, a partir do qual poderiam expressar suas opinióes e explicar, com a ajuda de exemplos, as noçóes teóricas trabalhadas ao longo do semestre, correspondentes às concepçóes de diversidade e variação linguística, suas manifestações na língua-alvo e sua aplicabilidade e importância no ensino do inglês.

No questionário em questão, os aprendizes tiveram a oportunidade de caracterizar três diferentes construtos: "variação linguística”, "erros em língua materna e língua estrangeira" e "variedades da língua inglesa”. Os alunos foram solicitados a expressar, separadamente, tanto as suas concepçóes prévias ao projeto, quanto as suas visóes após a execução do ciclo pedagógico.

\section{Análise das respostas fornecidas nos questionários de avaliação}

Nesta seção, objetivamos discutir as respostas fornecidas pelos participantes do projeto no questionário distribuído ao término do trabalho pedagógico. A discussão está organizada em três eixos: concepções sobre variação linguística; sobre erro em língua materna e língua estrangeira; e sobre variedades de língua inglesa.

Ao descreverem as suas concepçóes prévias, todos os aprendizes mencionaram que as questóes relacionadas à discussão sobre variação linguística não constituíam um assunto novo, afirmando que já haviam recebido formação teórica em disciplinas cursadas em etapas anteriores do curso.

Ainda que a questão não se caracterizasse como nova, verificamos, mais uma vez, uma confusão entre os conceitos de "variação linguística" e "variedades" linguísticas. Tal confusão pôde ser verificada não somente nos relatos referentes às concepçóes prévias ao trabalho realizado, mas, também, nas descriçôes das concepçóes elaboradas posteriormente à execução do projeto. Os trechos que seguem ilustram essa questáo: 


\section{Informante 2:}

Concepçôes prévias: Variaçóes na língua que acontecem em diversas circunstâncias, por exemplo classe social, região onde a língua é falada, etnia, influência de outras línguas. É um fenômeno já conhecido, mas dificilmente aceito pelos falantes, da que é considerada a lingua padrão.

Visóes posteriores ao curso: Não mudou muito, mas agora também vejo a linguagem escrita na Internet como um tipo de variação

De acordo com a resposta transcrita acima, o Informante 2 atribui a variação linguística à existência de variedades consideradas não-padrão ("dificilmente aceito pelos falantes"), referindo-se a diferentes variedades como "tipos de variação". A resposta que segue, fornecida pelo Informante 3, caracteriza a variação linguística como "diferentes formas" de expressão, evidenciando, mais uma vez, uma confusão entre as noções teóricas de "variação", "variedade" e "variantes".

\section{Informante 3:}

Concepçôes prévias: Diferentes formas de expressão verbal (formallinformal, variação conforme classe social, etc.). A maior parte desses conceitos aprendi nas cadeiras de linguistica.

Também ao tratarem de variação linguística, observamos, nas respostas fornecidas, uma ênfase bastante grande nos fatores sociais que dão conta da variação. Em nenhuma das respostas providas pelos 12 participantes foi, de fato, mencionado o papel dos condicionadores linguísticos sobre os fenômenos variáveis, conforme pode ser exemplificado na resposta que segue:

\section{Informante 1:}

Concepçôes prévias: A lingua não é estática, ocorrem variaçôes históricas, geográficas, sócio-econômicas, etc. Não existem variedades certas ou erradas, mas algumas têm mais prestígio, por questóes externas ao funcionamento da lingua (concep̧̧óes adquiridas nas disciplinas de linguistica do curso, vistas anteriormente).

Visôes posteriores ao curso: as mesmas, porém, creio que agora sou mais capaz de falar sobre, provavelmente por ter tido mais exposiçâo ao tema. 
Verificamos que, mesmo antes da execução do projeto, fatores sociais eram considerados, pelos alunos, como os únicos condicionadores da variação linguística. Essa visão parece permanecer após a execução do projeto, visto que, mesmo nas respostas referentes às novas visóes obtidas após o ciclo pedagógico, condicionadores linguísticos não foram mencionados como importantes para o processo de variação. Mesmo assim, vemos, na resposta de um dos informantes (Informante 5), uma preocupação em deixar claro o caráter sistematizável da variação linguística.

\section{Informante 5:}

Concepçöes prévias: Antigamente, admitiam a variação, mas acreditavam que não era possivel sistematizá-la. Estudos posteriores mostraram que pode existir sistematização na variação linguistica.

No que diz respeito especificamente às novas concepçóes, oriundas do projeto de ensino realizado junto à turma, a grande maioria dos participantes admitiu não se tratar de "novos conhecimentos", mas, sim, de um "reforço" de conceitos já estudados. As respostas dos aprendizes se caracterizaram por ressaltar a importância de uma reflexão sobre o fenômeno de variação linguística com dados de língua inglesa, reflexão essa que constituiu uma novidade possibilitada pelo projeto.

Informante 10:

Visóes posteriores ao curso: O contato com variaçóes linguísticas que acontecem dentro da língua inglesa foi um conteúdo novo que me foi apresentado.

\section{Informante 11:}

Visóes posteriores ao curso: A cadeira Inglês $V$ adicionou novos conhecimentos aos que eu já tinha a respeito de variaçóes linguísticas. No entanto, os novos conhecimentos apenas fortaleceram minhas concepçóes prévias sobre o tema.

Os participantes reconhecem, também, a importância de tal discussão para sua formação docente: 
Informante 4:

Visöes posteriores ao curso: Minha visão atual mudou porque não tinha essa noção de variação na língua inglesa. Acredito que estudar variação linguistica acrescenta muito à minha formação acadêmica, principalmente quando me imagino dando aulas.

Ao se referirem às vantagens de estudar exemplos de variação linguística nas aulas de língua inglesa, apesar de muitas vezes os alunos confundirem os conceitos de variação e variedade, ficou claro o fato de o projeto de ensino ter expandido seus conhecimentos.

Informante 8:

Visóes posteriores ao curso: Expandi meus conhecimentos a respeito das diferentes variedades linguisticas na língua inglesa, não só AmE e BrE.

Informante 10:

Visöes posteriores ao curso: $O$ contato com variaçóes linguísticas que acontecem dentro da lingua inglesa foi um conteúdo novo que me foi apresentado.

Em suma, podemos dizer que o projeto de ensino, além de consolidar conceitos previamente estudados no curso, buscou possibilitar o estudo de fatos variáveis da língua estrangeira. $\mathrm{O}$ projeto foi bem recebido pelos participantes: com a verificação da variação em dados do inglês, expandiram-se seus conhecimentos sobre a própria língua estrangeira.

A noção de "erro" em língua materna, segundo os aprendizes, também já havia sido trabalhada nas cadeiras de Linguística no início do curso. No que diz respeito a essa questão, os aprendizes afirmam, portanto, que o projeto pedagógico desenvolvido, mais uma vez, representou um reforço de concepçôes já firmadas, conforme pode ser verificado nas respostas que seguem.

Informante 1:

Concepçóes Prévias: Não existe "erro" em língua materna. Existem desvios da norma padrão.

Visóes posteriores ao curso: Idem à anterior. 
Informante 6:

Concepçôes Prévias: As concepçóes de erro em lingua materna também já estavam sólidas, de que falantes nativos não erram, etc.

Os aprendizes afirmam já ter "bases sólidas" a respeito da concepção de erro em língua materna, mas as respostas fornecidas parecem, de certa forma, remeter a um senso comum de que "erros não existem", sem ser discutida, com muito afinco, a noção das questóes de apropriação do uso ou não da variedade padrão. Encontramos poucas respostas que se voltassem ao status gramatical ou agramatical das estruturas, que referissem erro como agramaticalidade, como aquilo que inviabiliza a comunicação.

\section{Informante 10}

Erros cometidos por não seguir à risca as regras aplicadas pela gramática tradicional não acarretam necessariamente falhas de comunicação. O erro nesse caso é relativo.

Ao se referirem a suas concepções prévias sobre erro em língua estrangeira, os aprendizes tendem a seguir dois padrões de resposta: ou afirmam não ter pensado sobre a questão antes da execução do projeto, ou atribuem a noção de erro a questôes referentes ao processo de aquisição de segunda língua, como pode ser observado nas citaçóes que seguem:

\section{Informante 1:}

Concepçóes prévias: $O$ erro em $L E$ se dá pelo não-aprendizado de certo aspecto.

Informante 2:

Concepçóes prévias: Erros em língua estrangeira geralmente são causados pela influência da estrutura.

\section{Informante 12:}

Concepçóes prévias: Muitos erros ocorrem devido à forte influência da língua materna no momento da aprendizagem da lingua estrangeira. 
Nas três respostas aqui transcritas, que caracterizam a maioria dos comentários fornecidos pelos participantes, o erro é atribuído a um problema desenvolvimental, ocasionado tanto pela complexidade da estrutura a ser adquirida da língua estrangeira (Informante 2) como pela ação da transferência dos padróes da língua materna (Informante 1).

Uma comparação entre as caracterizaçôes fornecidas para erros em língua materna (LM) e língua estrangeira (LE) merece destaque. Primeiramente, ao contrário do que foi verificado nas respostas referentes à LE, aspectos de ordem estrutural não foram mencionados na caracterização de erros em LM. Além disso, os aprendizes tendem a não entender como erro realizaçóes da LM desviantes das normas da gramática tradicional, porém inteligíveis, mas tendem a considerar erradas tais realizaçóes na LE quando produzidas por um falante não nativo. O erro parece "mais errado" em língua estrangeira do que em língua materna. Por exemplo, uma realização como He don't work here (Ele não trabalha aqui), que não pertence à variedade padrão do inglês, não seria errada se produzida por um falante nativo da língua-alvo, mas seria erro se produzida por um aprendiz de inglês como língua estrangeira, ainda que tal estrutura seja efetivamente utilizável em diversas variedades do inglês. A concepção prévia dos aprendizes era a de que a língua-alvo possui, basicamente, uma única variedade: a padrão, de modo que quaisquer produçóes que divergem dessa variedade, quando realizadas por aprendizes da língua-alvo, constituam erros. Ainda que os aprendizes já chegassem à cadeira de Língua Inglesa V com um conhecimento solidificado de diversidade linguística na língua materna, parece-nos que, no que diz respeito ao uso da língua estrangeira, tal noção era por eles ignorada. Na verdade, de todas as respostas referentes às concepçóes prévias ao projeto, apenas uma traz a questão da gramaticalidade e da inteligibilidade à discussão. Na resposta a seguir, o Informante 7 atribui o status de erro àquelas estruturas que acarretam problemas de inteligibilidade na comunicação, independentemente de essas estruturas pertencerem à língua materna ou à língua estrangeira.

\section{Informante 7:}

Concepçóes prévias: Utilização de formas que impossibilitem a comunicação.

No que diz respeito ao relato das concepçóes estabelecidas posteriormente ao curso, verificamos que, mesmo após o desenvolvimento das atividades, 
muitos aprendizes se mostravam receosos sobre a concepção de erros em segunda língua.

\section{Informante 9:}

Visóes posteriores ao curso: Tenho que estudar mais sobre erro em língua estrangeira. Achei pouco estudado no curso.

De fato, ainda que os conceitos de variação e preconceito linguístico tenham sido amplamente implementados ao longo das aulas, parece-nos que os aprendizes ainda sentiram, ao final dos encontros, uma carência no que diz respeito a um possível status diferenciado do erro em LE. Tais dúvidas, novamente, advêm da concepção que atribui um status diferente para as formas destoantes do padrão em LM e LE, conforme verificado na discussão das concepçóes prévias ao curso. Isso também se reflete no fato de que a maioria expressou que suas concepçóes prévias ao curso se mantinham, após a intervenção pedagógica. Assim, ainda que os aprendizes reconheçam a diversidade da língua inglesa, tal diversidade parece mostrar-se como um privilégio apenas do falante nativo, uma vez que o estrangeiro continuará a ser considerado errado se não fizer uso da norma padrão.

Apesar da concepção acima, expressa por alguns dos aprendizes, encontramos algumas diferentes concepções após a realização do curso, conforme mostramos com o texto fornecido pelo Informante 5 .

\section{Informante 5:}

Concepçóes prévias: Eu nunca tinha parado pra pensar na variação na língua estrangeira.

Visóes posteriores ao curso: O erro está associado à agramaticalidade. Para a variação na língua, podemos dizer que aquilo é adequado ou não para determinado ambiente, contexto, etc.

Alguns alunos relataram se sentir mais "esclarecidos" sobre a noção de erro em LE, mas apenas o Informante 5 trouxe à discussão questóes referentes à gramaticalidade, à inteligibilidade e à apropriação.

Em suma, sobre as concepçóes de erro dos aprendizes, verificamos que, embora todos já reconheçam a existência de variedades na língua inglesa, há 
um pensamento vigente de que, ao aprendiz de LE, cabe somente o uso da forma-padrão. Verificamos, nas respostas fornecidas, um status distinto no uso linguístico dessas formas não padrão: se utilizadas pelos falantes nativos do idioma, tais formas podem ser consideradas aceitáveis. Se utilizadas pelo aprendiz não-nativo, tais formas caracterizam algo indesejável. Ao aluno, caberia a aprendizagem de uma língua inglesa ideal, sem que lhe fosse permitido fazer uso da diversidade linguística.

As respostas referentes ao item "variedades de língua inglesa" parecem evidenciar a maior contribuição, para os alunos, prestada pelo projeto executado. Na maioria delas, os aprendizes deixaram claro que o projeto pedagógico representou uma oportunidade de observar a diversidade da língua inglesa, resumida, pelos manuais de ensino de língua vigentes, somente às variedades britânica e americana.

\section{Informante 4:}

Concepçóes prévias: Antes tinha apenas o conhecimento do inglês americano e o britânico. Nunca tinha estudado com tanta ênfase as diferentes variaçóes da lingua inglesa. Apenas no $1^{\circ}$ semestre, no qual apresentei o trabalho sobre "Jamaican English". No entanto, não tinha a visão que tenho hoje sobre essa variedade.

Visóes posteriores ao curso: Esse semestre me acrescentou em conhecimento sobre as variedades de língua inglesa. Acredito que seja o tópico de inglês que seja o mais útil, principalmente para quem quer ser professor.

\section{Informante 6:}

Concepçôes prévias: Idéias básicas das diferenças entre UKe US English.

Visão posterior ao curso: Aprofundamento nas variedades que já conhecia. Conhecimento de novas: Black English, Jamaican Creole, Canadense, etc.

\section{Informante 7:}

Concepçôes prévias: Eu tinha pouca noção das variedades da lingua inglesa para além de expressóes utilizadas em músicas.

Visóes posteriores ao curso: Conseguimos abranger as variedades regionais, relacionadas à geração, à classe social e também a países. Além disso, nos apropriamos um pouco das variedades da lingua escrita em meios digitais. 


\section{Informante 11}

Concepçôes prévias: Não conhecia nada. Era completamente ignorante mesmo em relaçâo às diferenças entre o inglês americano e o britânico.

Visóes posteriores ao curso: Nesse aspecto, houve uma evolução significativa. Conheci novas variedades e achei muito interessante. Já sou capaz, inclusive, de distingui-las entre si.

Apesar de considerarmos bastante positivo o retorno dos alunos ao insumo recebido sobre variação linguística (processo) e variedades (produto), verificamos, mais uma vez, que os aprendizes apresentam dificuldade para diferenciar essas noções. De fato, além de, em diversas respostas, os termos serem confundidos, houve casos em que tal item do questionário foi deixado em branco, sob a alegação de que a resposta para tal questão já havia sido fornecida no item referente à "variação linguística".

Enfim, a análise da questão evidenciou que este foi o ponto em que os aprendizes mostraram-se mais positivos com relação à implementação do projeto de ensino, por representar a descoberta de um mundo novo. Os alunos acharam relevante a apresentação e o contato com as diversas variedades da língua estrangeira, o que foi possibilitado por uma abordagem que conciliava insumos teóricos com o uso efetivo da língua.

\section{Informante 5}

Foi interessante o trabalho em inglês ser associado a filmes, desenhos e músicas. Isso aproxima um estudo teórico da realidade dos alunos.

Julgamos, dessa forma, o contato com as variedades do inglês, possibilitado pelo projeto, como bastante relevante para os profissionais em formação.

\section{Conclusão}

A partir das observaçóes feitas ao longo do desenvolvimento do projeto de ensino, e, sobretudo, das respostas fornecidas pelos participantes ao questionário de avaliação, concluímos que o trabalho realizado prestou uma contribuição para a conscientização dos alunos acerca das variedades da língua inglesa. Tal conscientização, de acordo com as respostas dos próprios alunos, 
mostra-se bastante proveitosa para futuros professores e tradutores.

As respostas fornecidas permitiram-nos, ainda, refletir sobre diversas questôes referentes às concepçôes de língua e variação linguística trazidas pelos alunos, bem como repensar alguns aspectos para próximas ediçóes de aplicação do projeto em questão. Verificamos que, embora os conceitos sobre variação e diversidade linguística não se mostrassem novos aos aprendizes, ainda era grande a dificuldade de operacionalização de tais conceitos. Mais do que isso, julgamos que se mostra importante uma reflexão sobre os fatores condicionadores da variação linguística. A verificação das respostas dos alunos evidenciou que os aprendizes priorizam os aspectos sociais, enquanto os fatores linguísticos condicionadores dos fenômenos variáveis tendem a ser desconsiderados.

A observação das respostas permitiu-nos, também, refletir a respeito do status atribuído ao uso das diversas variedades linguísticas por parte de falantes nativos e falantes estrangeiros. Sob as concepçóes expressas pelos alunos, se, por um lado, parece que o falante nativo pode utilizar-se das diversas variedades de que a língua dispóe, o aprendiz de língua estrangeira precisa confinar-se à norma padrão. Em outras palavras, embora, como falantes e ouvintes, os participantes deste estudo experimentem e reconheçam a variação linguística na LE, tais alunos parecem reproduzir as premissas de um ensino/aprendizado de uma língua ideal, caracterizada pela variedade padrão, geralmente preconizada nos manuais de ensino de língua estrangeira. Nesse conflito entre a língua real e a ideal, os alunos tendem a reproduzir a premissa de que aprendizes de língua estrangeira não podem utilizar-se da variedade linguística tal como o faz um falante nativo.

Ainda que não seja o objetivo deste artigo discutir os diversos e complexos fatores ocasionadores dessa premissa, bem como encontrar uma solução pontual para a questão, acreditamos que o trabalho com a diversidade linguística da língua estrangeira, conforme o realizado ao longo do projeto de ensino aqui descrito, venha a contribuir para uma mudança dessa concepção. Encerramos o presente artigo, portanto, chamando a atençáo para a necessidade de açôes conjuntas, entre professores de Teoria Linguística e Língua Estrangeira, que visem a demonstrar, através da exposição da língua em uso, os conceitos abordados nas aulas teóricas dos cursos de Letras. Cremos que essa parceria, pelo fato de unir conceitos e áreas de conhecimento que se relacionam ine- 
rentemente, apesar de muitas vezes tratados separadamente nas universidades, mostra-se de grande importância para a formação dos profissionais de língua inglesa.

\section{Referências}

BLOM, J.-P.; GUMPERZ, J.J. O significado social na estrutura linguística: alternância de códigos na Noruega. In: RIBEIRO, B.T.; GARCEZ, P.M. (Orgs.) Sociolinguistica interacional. 2.ed. São Paulo: Loyola, 2002 [1972]. p. 45-84.

CHAMBERS, J.K. Studying language variation: An informal epistemology. In: CHAMBERS, J.K.; TRUDGILL, P.; SCHILLING-ESTES, N. (Eds.) The Handbook of Language Variation and Change. Malden/Oxford: Blackwell, 2002. p. 3-14.

ECKERT, P. Linguistic variation as social practice. Malden/Oxford: Blackwell, 2000 .

GREEN, L. Syntactic variation. In: Sociolinguistic variation: theories, methods and applications. Cambridge: Cambridge University Press, 2007. p. 24-44.

GUY, G.R.; BOBERG, C. Inherent variability and the obligatory contour principle. Language variation and change 9, 1997. p. 149-164.

LABOV, W. Sociolinguistic patterns. Philadelphia: University of Philadelphia Press, 1972.

Blackwell, 1994.

. Principles of linguistic change - internal factors. Malden/Oxford: Principles of linguistic change - social factors. Malden/Oxford: Blackwell, 2001.

. Padróes sociolinguísticos. São Paulo: Parábola Editorial, [1972] 2008.

LASS, R. Historical linguistics and language change. Cambridge: Cambridge University Press, 1997.

TRASK, R. L. Historical linguistics. London: Arnold, 1996. p. 1-16. 


\title{
TITLE: LANGUAGE VARIATION AND DIVERSITY IN THE TEACHING AND LEARNING OF UNDERGRADUATE LEARNERS OF ENGLISH: DISCUSSING THE VIEWS OF FUTURE PROFESSIONALS
}

\begin{abstract}
The paper describes and discusses a teaching project on language variation and linguistic diversity in undergraduate courses of English for professional purposes in Brazil. In this paper, the process of language variation in natural languages is characterized, variable facts of the English language are approached, and the theoretical basis of the project, as well as its implementation and results, are presented.

KEY WORDS: language variation; English language; undergraduate programs of English language for professional purposes.
\end{abstract}

Recebido em: 30/08/2013

Aprovado em: 20/12/2013 